\title{
Gestão da Pesquisa em Think Tanks: notas sobre a eXPeriênCIa recente da Diest ${ }^{1}$
}

Flávia Schmidt²

Janine Mello ${ }^{3}$

\section{INTRODUÇÃO}

Think tanks podem ser geralmente definidos como organizaçôes de análise e engajamento de políticas públicas que geram pesquisa orientada para políticas, análise e aconselhamento sobre questôes nacionais e internacionais estruturadas em órgãos permanentes e não como comissões $a d$ hoc (McGann, 2020). "Trata-se de um conceito que já foi apontado como "essencialmente contestado" (Medvetz, 2008), e definiçóes alternativas já foram indicadas, contudo essa pode ser considerada uma definição mainstream, como destacam Vianna, Coelho e Cunha (2019). A adoção de definiçóes comuns para think tanks também já foi rejeitada por autores como Garcé e Abelson (2006) e Rigolin e Hayashi (2012).

Em 2018, existiam 8.248 think tanks no mundo, entre os quais 1.043 eram sediados na América Latina e 103 no Brasil (McGann, 2020). No mesmo documento, o Ipea é indicado como o sétimo melhor think tank da América Latina e o $24^{\circ}$ melhor entre os 73 think tanks governamentais existentes.

O Ipea é uma fundação pública atualmente vinculada ao Ministério da Economia cuja missáo é aprimorar as políticas públicas essenciais ao desenvolvimento brasileiro, por meio da produção e disseminação de conhecimentos e da assessoria ao Estado nas suas decisóes estratégicas. Sua estrutura organizacional conta com sete diretorias, entre as quais seis têm como competência a realização de estudos e pesquisas. A Diest foi criada em 2010, na última restruturação organizacional ampla do Ipea, ${ }^{5}$ juntamente com a Diretoria de Estudos e Relaçôes Econômicas e Políticas Internacionais (Dinte), sendo, assim, uma das unidades organizacionais mais recentes do instituto.

A partir de um breve referencial teórico que indica os principais desafios contemporâneos da gestão em think tanks, este artigo tem como objetivo apresentar algumas açóes adotadas na Diest como esforços para lidar com um contexto de atuação crescentemente complexo. O trabalho estará focado apenas no registro dos esforços de gestáo feitos, de modo que os resultados e impactos desses esforços não serão analisados.

Além desta introdução, o texto está dividido em seis seçôes. A próxima reúne algumas contribuiçóes da literatura sobre a gestão de think tanks. A seguir, apresentam-se três açóes recentes adotadas pela Diest. Por fim, são tecidas algumas considerações finais.

1. DOI: http://dx.doi.org/10.38116/bapi29art2

2. Técnica de planejamento e pesquisa e diretora na Diretoria de Estudos e Políticas do Estado, das Instituições e da Democracia (Diest) do Ipea.

3. Especialista em políticas públicas e gestão governamental e coordenadora-geral na Diest/lpea.

4. Ainda que não exista um consenso sobre a definição mais adequada dessas instituições, esta definição é suficientemente ampla para os objetivos deste trabalho.

5. Decreto no 7.142, de 29 de março de 2010. 


\section{GESTÃO EM THINK TANKS}

Ao produzir conhecimento a partir da adoção de métodos científicos, os thinks tanks contribuem para fomentar discussões mais robustas, ampliar o debate sobre temas de interesse público e viabilizar processos de tomada de decisão mais bem informados. ${ }^{6}$ Pelo menos três pontos são importantes para alcançar efetividade nesse processo: pesquisas teórico-metodologicamente consistentes, articulação próxima com os decisores e uma boa gestão. Não é infrequente, contudo, que a gestão deixe de ser tratada como prioridade em instituiçóes dessa natureza pelos dirigentes, em razáo de seus backgrounds predominantemente acadêmicos ou governamentais (Struyk, 2006). O argumento deste trabalho é que a realização de pesquisas de excelência e a proximidade institucional com o centro de governo não podem prescindir de investimentos em esforços por parte das instituiçóes no pilar gestão.

A despeito da definição adotada, é importante destacar que, sob o guarda-chuva conceitual de think tanks, há organizaçôes muito diferentes entre si. Weaver (1989), por exemplo, oferece uma taxonomia com três tipos: "universidades sem alunos"; organizaçóes de pesquisa por contratos; e think tanks de defesa e lobby de direitos (advocacy). Uma lista mais extensiva, mas náo necessariamente exaustiva, é oferecida por M cGann (2020)M): instituições autônomas e independentes; quase independentes; afiliadas a governos; quase governamentais; afiliadas a universidades; afiliadas a partidos políticos; e instituições corporativas que visam ao lucro. Em uma das escassas análises não focadas em casos europeus ou anglo-saxônicos Braun, Cicioni e Ducote (2000) definem, a partir do caso argentino, que think tanks poderiam ser classificados bidimensionalmente: em relação à sua orientação (foco em pesquisa ou em implementação) e em relação ao nível de ação (local ou nacional).

Duas dimensões em especial merecem ser destacadas nas taxonomias citadas, uma vez que possuem impactos diretos na escolha de estratégias de gestão diferenciadas. Uma se refere à existência ou não de vínculos com outras instituições, sejam elas governos, universidades, grupos econômicos ou mesmo partidos políticos. A outra, particularmente imbricada ou mesmo derivada da primeira, trata da sua autonomia, tanto em aspectos de gestão e governança como de agenda e modo de operação. Ainda levando em conta que a produção de conhecimento e a busca por influência podem ser consideradas algo comum entre os think tanks de diferentes posições nessas dimensões, é razoável supor que o lugar que eles ocupam não diga apenas muito sobre o que e como eles "falam", mas que adicionalmente imponha desafios particulares à gestáo.

Adicionalmente às questóes ligadas ao ambiente em que essas instituiçóes estáo inseridas, Braun et al. (2007) propóem um modelo analítico em que variáveis endógenas e exógenas são consideradas. Resumidamente, as variáveis endógenas contemplam liderança e gestáo institucional (gestão organizacional, recursos humanos e financiamento), gestão da pesquisa (seleção de temas, características e processos da pesquisa) e comunicação (estratégias e ferramentas para comunicação institucional, difusão da pesquisa, relacionamento com formuladores de políticas e outros atores importantes). Entre as exógenas, figuram variáveis estruturais, macropolíticas e econômicas e político-institucionais, como a existência de demanda política para a pesquisa, abertura à participação, janelas de oportunidade para impacto sobre as políticas ${ }^{7}$ e nível de capacidades governamentais. O êxito ou fracasso das instituições em exercer influência na definição, formulação, implementação e avaliação de agendas

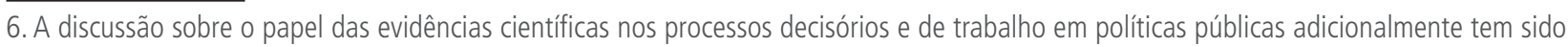
feita internacionalmente - entre outros trabalhos, citamos Cairney (2016). No Brasil, o debate vem se ampliando, e destacamos a atuação do projeto em andamento da Diest 0 que Informa e o que Não Informa as Políticas Públicas no Brasil?, com publicações como Pinheiro (2020). 7. Como exemplos dessas janelas de oportunidade, os autores citam crises econômicas, políticas ou sociais e ainda novos governos. 
estaria, assim, relacionado ao reconhecimento da dinâmica do possível alinhamento dessas variáveis como orientadoras da ação para a decisão de quando e como contribuir melhor.

Em uma contribuição de caráter mais prescritivo, Struyk (2006) sintetiza onze tópicos em torno dos quais organiza a sua obra, sugerindo os desafios e as principais áreas de atuação da gestão de think tanks:

- motivação da equipe para ser produtiva e retenção de pessoas, com políticas de avaliação, treinamento e remuneração;

- organização de treinamentos de alta relevância;

- garantia de controle de qualidade do produto apresentado aos clientes, principalmente por meio de um processo de revisão por pares;

- comunicaçáo eficaz dos resultados da pesquisa aos formuladores de políticas e ao público em geral;

- obtenção dos melhores resultados junto ao conselho administrador ou à diretoria, envolvendo-os não apenas nas questôes de gestão como também na orientação estratégica à instituição;

- desenvolvimento de novos produtos e serviços e identificação de novos clientes e outras oportunidades;

- compreensão da dinâmica da concorrência por contratos governamentais;

- determinação da taxa de overhead adequada;

- geração de informações essenciais para a alta direção sobre as atividades da organização;

- $\quad$ estruturação de equipe de pesquisa e de suas composições; e

- desenvolvimento de lideranças de equipe (gerentes de nível médio).

No caso do Ipea, por exemplo, objeto deste artigo, a estruturação como uma fundação pública vinculada ao Ministério da Economia - e, portanto, um think tank governamental - traz a possibilidade de autonomia da gestão administrativa, mas também a necessidade de que as agendas em desenvolvimento estejam alinhadas às exigências do Estado.

Não se pretende neste trabalho oferecer um modelo fechado para lidar com os desafios mencionados até aqui - ligados ao tipo de organização, suas condições internas, ambiente em que atua e questões de operação que devem ser consideradas na gestão. A próxima seção avança e registra três ações adotadas pela Diest nos últimos anos que correspondem a campos de ação centrais em think tanks e que têm resultado em alteraçóes na inserção da diretoria: a construção da agenda, a intensificação do uso de dados e a disseminação do conhecimento produzido.

\section{A EXPERIÊNCIA RECENTE DA DIEST}

À Diest competem a promoção e a realização de estudos e pesquisas em questôes ligadas à estrutura, à organização e ao funcionamento do Estado brasileiro e de seus aparatos institucionais, bem como aos modos de relação entre o Estado e a sociedade nos processos de políticas públicas para o desenvolvimento. Suas principais áreas de pesquisa têm sido organizadas no período recente em torno de três eixos: i) justiça, direitos humanos e segurança pública; ii) governança e capacidades estatais; e iii) instituições e desenvolvimento. 
A diretoria conta com 36 pesquisadores permanentes em sua equipe, ${ }^{8}$ de diversas áreas do conhecimento. Como pesquisadores permanentes ${ }^{9}$ são considerados servidores públicos integrantes das carreiras de planejamento e pesquisa (carreira própria do Ipea); planejamento e orçamento; e especialistas em políticas públicas e gestão governamental, que atuam nas atividades de pesquisa aplicada, assessoramento governamental e representação institucional desenvolvidas pela Diest. ${ }^{10}$

A natureza da missão institucional do Ipea enseja a inserção predominante de seus pesquisadores em assessoramento governamental e projetos coletivos de pesquisa. A agenda dos pesquisadores deve ser idealmente pautada por um equilíbrio dinâmico entre essas duas atividades: a excelência no assessoramento governamental e na qualificação das políticas públicas em um think tank governamental é sempre retroalimentada pela realização de pesquisas robustas e aplicadas. A aplicabilidade tem sido uma das diretrizes formais de gestão na diretoria nos últimos anos. No caso da pesquisa aplicada, vale distinguir, grosso modo, a atuação dos pesquisadores em projetos de natureza coletiva e projetos de pesquisa individuais; mesmo com a diretriz de foco em projetos de maior escala, não é raro, contudo, que iniciativas individuais acabem resultando em projetos mais amplos e coletivos e que a inserção em determinados projetos de pesquisa coletivos resultem em eventuais reformulaçóes de agendas individuais. ${ }^{11}$

As diretrizes de gestão definidas atualmente pela direção da Diest são aplicabilidade da pesquisa, excelência, definição clara de prioridades, abertura para o fluxo de ideias e inserção na qualificação do debate público. A partir dessas diretrizes, foram definidas algumas linhas de ação prioritária para a organização do trabalho interno da diretoria, que serão retomadas nas seçôes a seguir.

\section{CHAMADA INTERNA DE PROJETOS DE PESQUISA}

A construção de agendas de pesquisa é um dos maiores desafios na gestão de think tanks. Se o desenvolvimento de projetos de pesquisa que contemplem aplicabilidade, integraçáo, excelência e impacto, entre tantas outras características desejáveis, é uma tarefa bastante complexa ao nível institucional, igualmente o é no âmbito das unidades organizacionais de pesquisa maiores, como é o caso da Diest. Diferentes modelos para chegar a uma agenda podem ser adotados e a história do Ipea registra caminhos diversos já percorridos nesse objetivo.

No Ipea, os diretores das áreas têm autonomia para a definiçãa dos projetos que comporão os planos de trabalho anuais e a alocaçáo de recursos - dentro dos limites internos previstos e anualmente deliberados pela Diretoria Colegiada - para os principais insumos das pesquisas. ${ }^{12}$ Desde 2019, no

8. Dados de 15 de setembro de 2020. 0 Ipea possuía, nesta data, 180 servidores atuando como pesquisadores permanentes.

9. Em instituições de pesquisas internacionais, os pesquisadores permanentes aqui referidos seriam os senior research fellows, full-time researchers ou resident staff.

10. Além dos pesquisadores permanentes, há o suporte de bolsistas de pesquisa, em diferentes níveis de formação - de graduandos a doutores -, contratados de acordo com a necessidade de projetos específicos, constituindo uma equipe de trabalho em que há a dominância de pesquisadores permanentes e o uso de pesquisadores contratados de forma suplementar e flutuante.

11. Struyk (2006) oferece uma classificação adicional sobre a organização da pesquisa e as pessoas, em dois modelos: o modelo "carreira solo" e o modelo de equipes. No modelo carreira solo, pesquisadores "notáveis" trabalham de forma autônoma com o apoio de assistentes de pesquisa, na elaboração de trabalhos autorais. Já o modelo de times seria baseado em projetos de maior escala, tanto em relação a produtos como em relação ao número de produtos em cada projeto. É razoável afirmar que a atuação da Diest estaria em um modelo híbrido, orientado, contudo, para o modelo de times, predominantemente, sem que haja vedações ao desenvolvimento de projetos individuais, como exposto.

12. Entre os recursos a serem alocados, estão: bolsas do Programa de Pesquisa para o Desenvolvimento Nacional (PNPD), diárias e passagens e organização de eventos. 
âmbito da Diest, vem sendo adotado um modelo de seleção de projetos de pesquisa fundamentado em chamadas internas.

As chamadas têm contribuído para a composição de um modelo híbrido de construção de agenda. Parte dos recursos é alocada pela direção, especialmente na constituição de núcleos comuns de apoio ao trabalho de pesquisa (tratamento e análise de dados, por exemplo) e para uso em projetos de assessoramento governamental que não sejam realizados via Termo de Execuçáo Descentralizada.

Pelo processo das chamadas, todos os pesquisadores permanentes da diretoria podem submeter projetos, que são avaliados e selecionados de acordo com critérios predefinidos no instrumento de chamada. É importante destacar que, como já mencionado, a priorização da articulação da equipe em times e em projetos de maior escala não implica que outros projetos não possam ser aprovados pela direção para o plano de trabalho do ano. Para esses casos, os novos projetos ou a continuidade de projetos em andamento devem ser inicialmente discutidos no âmbito da respectiva coordenação e ter o aval dos coordenadores para encaminhamento à direção. A alocação de recursos, contudo, é feita, preferencialmente, para projetos selecionados via chamada. As chamadas têm como objetivos:

- direcionar a alocação de parte dos recursos orçamentários da Diest;

- selecionar projetos coletivos e de natureza aplicada, considerados prioritários pela sua relevância na pauta de políticas públicas do país, no âmbito das competências estatutárias da Diest;

- garantir um caráter sinérgico à agenda de pesquisa da diretoria;

- alavancar a capacidade de contribuição do Ipea para o assessoramento governamental e o debate público; e

- fomentar a articulação de redes, a integração e a cooperação com outros centros de pesquisa no Brasil e no exterior.

Os critérios de seleção de projetos foram definidos para alinhar a seleção aos objetivos do processo de chamada, como indica o quadro a seguir.

QUADRO 1

Critérios de avaliação

\begin{tabular}{|c|c|c|}
\hline Critério & Definição & Peso \\
\hline $\begin{array}{l}\text { Relevância do projeto para a agenda de políticas } \\
\text { públicas e da Diest }\end{array}$ & $\begin{array}{l}\text { - Contribuição da pesquisa para a área de atuação da Diest, com novos avanços em subáreas ou } \\
\text { linhas de pesquisa que ainda não estão bem desenvolvidas na instituição } \\
\text { - Caráter aplicado da proposta } \\
\text { - Produtos planejados }\end{array}$ & 3 \\
\hline Qualidade da proposta & $\begin{array}{l}\text { - Adequação da metodologia aos objetivos propostos } \\
\text { - Viabilidade de obtenção de dados e informações necessárias }\end{array}$ & 3 \\
\hline $\begin{array}{l}\text { Experiência do coordenador do projeto na coordenação } \\
\text { de projetos de pesquisa e assessoramento }\end{array}$ & $\begin{array}{l}\text { - Experiência do pesquisador na coordenação de projetos e grupos de pesquisa e a capacidade } \\
\text { demonstrada de nucleação de grupos de pesquisa }\end{array}$ & 2 \\
\hline Capacidade de articulação/integração & $\begin{array}{l}\text { - Integração de técnicos da Diest no projeto } \\
\text { - Parcerias e redes externas } \\
\text { - Contribuição para a internacionalização }\end{array}$ & 2 \\
\hline
\end{tabular}

Elaboração das autoras.

Após a submissão dos projetos, em um formato comum definido, todos são avaliados em duas etapas. É feita inicialmente uma análise prévia pela direção da Diest, em relação à aderência aos temas 
da chamada $;^{13}$ à experiência do coordenador do projeto na coordenação de projetos de pesquisa; e à articulação de redes, à integração e à cooperação com outros centros de pesquisa. Na segunda etapa, faz-se uma análise conjunta pelo Comitê de Seleçẫo formado pela direção da Diest (diretora e coordenadora-geral) e por técnicos de planejamento e pesquisa convidados de outras diretorias de pesquisa do Ipea (um de cada diretoria), no que concerne à relevância do projeto para a agenda de políticas públicas e da Diest e à qualidade da proposta (metodologia). Feita essa avaliação, a direção prevê ainda uma etapa de reunióes para ajustes com os coordenadores dos projetos com as melhores pontuaçôes, a fim de sugerir ajustes no orçamento proposto, nos produtos e/ou no escopo da proposta.

\section{PLATAFORMAS DE DADOS: MAPA DAS OSCS, ATLAS DA VIOLÊNCIA E ATLAS DO ESTADO BRASILEIRO}

Ao longo de sua trajetória, várias iniciativas de consolidação e disponibilização de bases de dados têm sido encampadas pelas diretorias do Ipea. Atualmente, estão sob a responsabilidade do instituto portais e plataformas virtuais já consolidadas e reconhecidas como referência em distintas áreas temáticas, como os casos do Atlas da Vulnerabilidade Social (AVS), do Atlas do Desenvolvimento Humano, do Ipea Data, do Atlas da Violência, do Mapa das Organizaçóes da Sociedade Civil (OSCs) e do Atlas do Estado. Essas iniciativas têm contribuído não apenas para disponibilizar à sociedade conjuntos estruturados de evidências sobre temas relevantes para o debate público, como segurança pública, desigualdade e formas de organização do Estado, mas também têm funcionado como instrumentos de divulgação e disseminação do trabalho realizado pelo Ipea e por seus parceiros.

Os ganhos do desenvolvimento de plataformas dessa natureza são múltiplos e perpassam esforços voltados para a democratização do conhecimento e a ampliação do acesso, público e gratuito, de diferentes setores da sociedade, informaçóes estratégicas sobre a realidade do país e, por fim, a criação de ferramentas de apoio à tomada de decisão de gestores públicos sobre políticas públicas e de fomento a novas pesquisas sobre os temas ali dispostos.

No entanto, a gestão dessas plataformas no âmbito de think tanks governamentais como o Ipea traz desafios relevantes que permitem repensar aspectos ligados ao planejamento prévio de projetos de pesquisa e seus produtos associados, assim como estratégias de internalização de competências e habilidades necessárias para o desenvolvimento e a manutenção desses instrumentos. O funcionamento dessas plataformas depende de atividades de desenvolvimento de ferramentas em ambiente web, de equipes aptas a gerir grandes bases de dados, de pesquisadores dedicados a analisar um volume significativo de dados, do atendimento de demandas vindas de setores da sociedade civil e da existência de equipes permanentemente disponíveis para atuar sobre problemas operacionais e de funcionamento que garantam a estabilidade do acesso pelos usuários da plataforma.

Um dos desafios centrais para a operacionalização adequada dessas iniciativas é que, de maneira distinta de outros projetos de pesquisa que possuem prazo de execução definido e equipes mais flexíveis e adaptadas às diferentes fases de desenvolvimento da pesquisa, plataformas como o Mapa das OSCs ou os atlas da Violência e do Estado possuem fluxo contínuo, são projetos sem data de finalização prevista e que requerem atualizaçóes periódicas. Isso traz repercussóes significativas nas formas de contratação possíveis para equipes envolvidas nesses projetos, no gerenciamento de riscos associados

13. Em 2019, não foram definidos temas em torno das quais as propostas deveriam ser concentradas, mas em 2020 decidiu-se que seriam prioritários processos em dois temas. 
à descontinuidade das iniciativas, além de tornar central a definição de estratégias de financiamento dessas plataformas, garantindo sua permanência em contextos de restrição orçamentária, por exemplo.

Atualmente, a Diest é responsável pela gestão de três das principais plataformas em funcionamento no Ipea: Mapa das OSCs, Atlas da Violência e Atlas do Estado. Para viabilizar suas atividades de rotina e o gerenciamento de suas funcionalidades, um ou mais pesquisadores permanentes são responsáveis pela coordenação técnica dessas plataformas, traduzidas sob a forma de projetos de pesquisa e de seus produtos correlatos - como aprimoramento e atualizaçóes das plataformas, publicaçóes, consolidação de novas bases de dados, produção de relatórios de pesquisa, entre outros. Além da coordenação técnica, a equipe de desenvolvimento e manutenção das plataformas com foco na área de tecnologia da informação (TI) e de interface com os usuários foi unificada sob a forma de um pool, que reúne pesquisadores associados com perfil para o desempenho dessas tarefas, responsável por atender às demandas das plataformas em funcionamento, assim como eventuais internalizaçóes de novas demandas por soluçóes web de disponibilização de dados e pesquisas da diretoria.

\section{PUBLICAÇÕES FOCADAS: O MODELO DO "BAPI TEMÁTICO"}

O Boletim de Análise Político-Institucional (Bapi) é uma publicação criada em 2011, organizada pela Diest, com o objetivo de publicar, em ediçóes semestrais, artigos sobre temas de relevância na vida política brasileira, com foco na agenda do Poder Executivo federal e em suas interfaces com o Congresso Nacional, as instâncias superiores do Judiciário e, de maneira mais ampla, os movimentos da sociedade.

Em 2017, a partir de um diagnóstico interno, ${ }^{14}$ foi feita uma reorientação da publicação, buscando diferenciá-la de outras publicaçóes do Ipea, como textos para discussão e livros. Assim, propôs-se uma nova configuraçáo para o boletim, que passaria a ser destinado a divulgar, para gestores públicos, pesquisadores e interessados, pesquisas recentemente concluídas ou em andamento do plano de trabalho da Diest, de seus pesquisadores e colaboradores, fomentando o debate a respeito da dimensão política e institucional do desenvolvimento. Ao definir esse novo público-alvo prioritário, houve a necessidade de adequação do formato dos artigos, com textos curtos e linguagem acessível.

Naquele momento, foi identificada pela direção uma janela de oportunidade, em que havia vários projetos da diretoria em fases de conclusão ou recém-concluídos, com resultados interessantes e ainda não publicados de forma consolidada em nenhum formato pelo Ipea. Propôs-se à equipe, então, que o boletim adotasse, por um período, um formato temático, com ediçóes dedicadas a compilar textos de cada um desses projetos.

Um cronograma inicial de publicações foi organizado pela coordenação-geral da diretoria, novas diretrizes editoriais foram definidas e cada edição passou a contar com editores ad hoc, que eram os coordenadores dos projetos cujos achados seriam compartilhados nas ediçóes temáticas. Assim, a partir da $11^{a}$ edição, foram publicadas treze edições temáticas. ${ }^{15}$

Além dos projetos em conclusão, o Bapi temático passou a ser adotado também como um dos principais veículos de disseminação dos novos projetos iniciados após 2017; acabou passando a funcionar como um veículo intermediário de disseminação de achados iniciais. Além da ampla adesão da equipe interna da Diest ao novo formato, observou-se que a organização das ediçóes foi 
bastante usada para a formação e o fortalecimento de redes de pesquisa com outros atores, o que pode ser constatado pela grande participação de autores externos convidados nas ediçóes. ${ }^{16}$ Em janeiro de 2019, reconstituiu-se o Comitê Editorial da publicação, formado por pesquisadores permanentes da diretoria. O comitê definiu que as ediçôes temáticas seguiriam sendo adotadas, assim como ediçóes com conteúdo heterogêneo e, ainda, aquelas compostas por artigos diversificados com dossiês temáticos.

\section{CONSIDERAÇÕES FINAIS}

Este artigo teve como objetivo apresentar algumas ações adotadas na Diest como esforços para lidar com o contexto de atuação complexo em que os think tanks estão inseridos. As açóes apresentadas correspondem a campos de ação centrais nessas instituiçóes: a construção da agenda, a intensificação do uso de dados e a disseminação do conhecimento produzido.

Como brevemente revisitado ao longo do texto, a gestão e o desempenho desse tipo bastante particular de organização vêm sendo discutidos nas últimas décadas diante de desafios ambientais bastante sérios, a exemplo da crise global do conhecimento. Há muito debate, muitas questóes, muitos níveis de atuação e possivelmente esforços ainda incipientes de gestão para o enfrentamento dos obstáculos brevemente tratados neste trabalho. Considerando que o conceito do que é um think tank, ainda que bastante contestado e mesmo rejeitado, reúne um grupo muito heterogêneo de instituiçôes, com destaque para a existência ou não de vínculo com outras instituiçôes e a consequente autonomia de ação, são enfrentadas ainda questóes particulares a cada tipo de instituiçáo. No caso do Ipea, um think tank governamental, é necessário considerar que a sua estruturaçáo formal como uma fundação pública ligada ao Ministério da Economia traz particularidades sutis que diferenciam o instituto de outras instituiçóes análogas.

Argumenta-se que a realização de pesquisas de excelência e a proximidade institucional com o centro de governo, pilares importantes em think tanks, são condições necessárias, mas não suficientes: mesmo - e possivelmente - instituiçóes constituídas por pesquisadores altamente qualificados não podem prescindir de investimentos em esforços equilibrados no pilar gestão. A experiência recente da Diest, uma das diretorias de pesquisa do Ipea, descrita aqui, pode contribuir para uma reflexáo mais ampla sobre como e o quanto tem sido feito nesse sentido.

Em um momento futuro, é desejável não apenas a ampliação desta discussão e do compartilhamento de práticas em nível institucional, mas também avançar para avaliar os resultados e impactos da gestão no Ipea.

Neste texto, foram mencionadas iniciativas adotadas no período recente no âmbito da diretoria, e cabe a reflexão adicional acerca do que não foi feito. Diversos desafios a serem enfrentados persistem, para não apenas assegurar sustentabilidade como aumentar o impacto nos próximos dez anos. Entre eles, há bastante espaço para o aperfeiçoamento na gestão de pessoas e equipes, nos processos de construção, no monitoramento e na avaliação de projetos, na comunicação eficaz dos resultados da pesquisa aos formuladores de políticas e ao público em geral e na gestão interna da informação e do conhecimento.

16. Todos os artigos, tanto dos pesquisadores permanentes como dos autores convidados, são sujeitos aos mesmos ritos de avaliação por pares. 


\section{REFERÊNCIAS}

BRAUN, M. et al. Lejos de “Thinktanklandia”: los institutos de investigación de políticas en los países en desarrollo. Buenos Aires: Cippec, 2007. Disponível em: <https://bit.ly/3dIxe45>.

BRAUN, M.; CICIONI, A.; DUCOTE, N. J. Should think tanks do policy implementation in developing countries? Lessons from Argentina. Buenos Aires: Cippec, 2000.

CAIRNEY, P. The politics of evidence-based policy making. London: Palgrave Macmillan, 2016.

GARCÉ, A.; ABELSON, D. E. Think tanks y políticas públicas en Latinoamérica: dinámicas globales y realidades regionales. Buenos Aires: Prometeo Libros Editorial, 2006.

HALL, J. L.; BATTAGLIO, R. P. Bridging the divide: when research speaks - and listens - to practice. Public Administration Review, v. 79, n. 4, p. 461-464, 2019. Disponível em: <https:// doi.org/10.1111/puar.13087>.

MCGANN, J. 2019 Global go to think tank index report. TTCSP Global Go To Think Tank Index Reports, 2020. Disponível em: <https://repository.upenn.edu/think_tanks/17>.

MEDVETZ, T. M. Think tanks as an emergent field. New York: Social Science Research Council, 2008.

PINHEIRO, M. M. S. Políticas públicas baseadas em evidências (PPBEs): delimitando o problema conceitual. Rio de Janeiro: Ipea, 2020. (Texto para Discussão, n. 2554). Disponível em: <https:// bit.ly/3n9Lg1Q>.

RIGOLIN, C. C. D.; HAYASHI, M. C. P. I. Por dentro dos "reservatórios de idéias": uma agenda de pesquisa para os think tanks brasileiros | Inside "think tanks": a research agenda for Brazilian think tanks. Liinc em Revista, v. 8, n. 1, 2012. Disponível em: <https://doi.org/10.18617/liinc.v8i1.460>.

STONE, D. L.; STONE, D.; CHAIR, M. C. Recycling bins, garbage cans or think tanks: three myths regarding policy analysis institutes. Public Administration, p. 259-278, 2007.

STRUYK, R. J. Managing think tanks: practical guidance for maturing organizations. Expanded 2nd ed. Budapest: Open Society Institute, 2006.

VIANNA, S. T. W.; COELHO, D. S.; CUNHA, A. dos S. Desenhos organizacionais e atuação de think tanks governamentais: uma análise comparativa internacional. Rio de Janeiro: Ipea, 2019. (Texto para Discussáo, n. 2472).

WEAVER, R. K. The changing world of think tanks. PS: Political Science and Politics, v. 22, n. 3, p. 563-578, 1989. 
